metrical development of the two sides of the body is of vital importance, and is strictly preserved by natural selection; but more or less defect of symmetry often occurs as a variation or monstrosity, and in cases where such asymmetry was useful these variations would be preserved and increased by selection and heredity. An altogether erroneous view is taken of the fact of effort being used in this case, as if it were something unusual. But in all cases selection produces changes which are useful and whose use is often indicated by effort. The giraffe uses effort in stretching its neck to obtain food during a drought; the antelope exerts itself to the utmost to escape from the leopard; but it is now recognized that it is not the individual change produced by this effort that is inherited, but the favourable constitution which renders extreme effort unnecessary, and causes its possessors to survive while those less favourably constituted, and who therefore have to use greater effort, succumb. In the case of the developing flat-fish also, the effort indicated the direction of the useful modification, and any variations tending either to the right kind of asymmetry or to a mobility of the eye, admitting its being twisted and retained in its new position, during the growth of the individual, would be certainly preserved.

I wish to take this opportunity of thanking Prof. Ray Lankester for his careful and appreciative review of my book. I am too well aware of my own deficiency in training as a naturalist not to admit all the shortcomings which he so tenderly refers to. It is quite refreshing to me to read at last a real criticism from a thoroughly competent writer, after the more or less ignorant praise which the book has hitherto received. I admit also that the term "laboratory naturalist," to which he demurs, was not well chosen. I meant it as the opposite, not so much to " field naturalist" as to "systematic naturalist" ; and it still seems to me that the gentlemen he refers to as not being "laboratory naturalists" are still less "systematic naturalists," in the sense of having specially devoted themselves to the observation, description, and classification of more or less extensive groups of species of living organisms.

Alfred R. Wallace.

\section{A Mechanical Illustration of the Propagation of a Sound.Wave.}

HAviNg to prepare some lectures on sound, I wished, if possible, to illustrate, without any very complicated apparatus, the way in which a sound-wave is propagated.

The following method suggested itself to me. As I have not met with the method while examining a large number of works on sound and wave motion, I venture to send a description of it to NATURE, as it may perhaps be of use to some students of acoustics.

A row of pendulums of equal length, $a, b, c \ldots . l$ (Fig. I) are suspended from a rod $A B$; in order to start the pendulums,

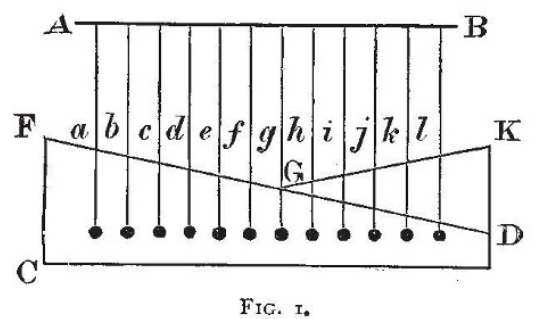

the bobs are held against an angular-shaped board, FCI, the rod being held in a plane slightly behind the plane of the board; if now the rod and pendulums be raised together vertically, $l$ will first swing, then $k$, and so on, till all are free: when the pendulums are raised with a uniform velocity, then each pendulum starts at an equal period of time after the one which is next to it ; the result is that a wave-motion is seen to run along the line of bobs as they vibrate to and fro. Such an arrangement has been used to illustrate wave-motion, as each bob moves with harmonic motion. But such an arrangement does not illustrate directly those compressions and rarefactions whereby sound is propagated. A slight movement, however, of the rod at once makes it do so. If, while the pendulums are vibrating, the rod from which they are suspended be turned in the horizontal plane through a right angle, the direction of the swing of each pendulum is not changed, and all the pendulums swing in the same plane. This will become clear from (Fig. 2), where the pendulum bobs viewed along ox appear to trace out wave-motion; the relative position of the bobs after the rod which supports them is turned through a right angle is shown along oy ; the motion then illustrates mechanically those movements of air-particles which, when in compression and rarefaction, propagate a sound-wave. If the rod be turned back through a right angle, the wave-motion is again restored. The illustration must be taken with the obvious defect, viz, that the bobs move in arcs, and not in straight lines.

Care should be taken that the amplitude of vibration be not greater than the distance between the points of suspension minus

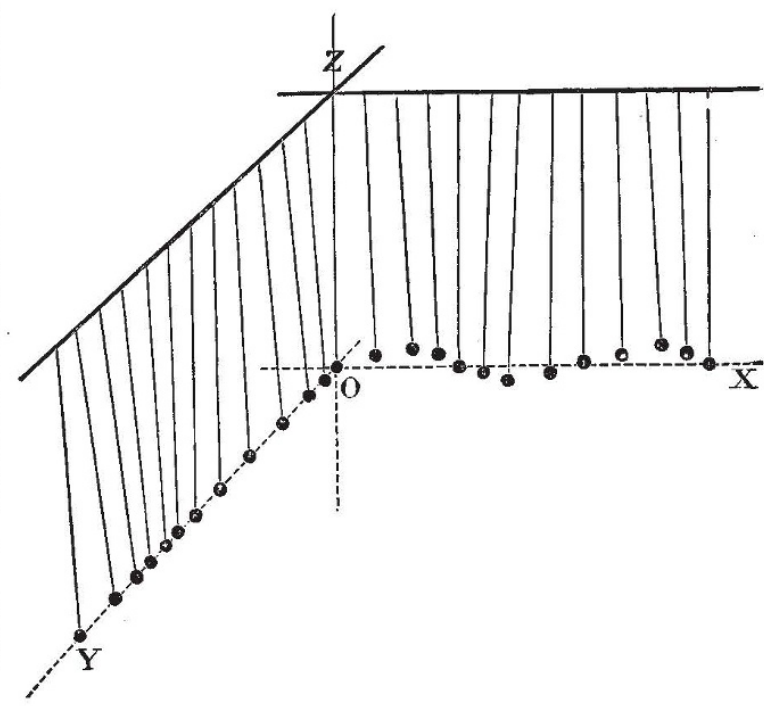

Fig. 2.

the diameter of a bob, otherwise the bobs will hit each other when vibrating in the plane $\mathrm{yz}$.

Twelve pendulums made of lead bullets $\mathrm{x} \cdot 5$ centimetre in diameter, suspended from threads 30 centimetres long, with a distance between each of 5 centimetres, were found to answer well by the author.

If the board used for starting the pendulums be made of the angular shape, FGK, then the movement of the bobs in their second position illustrates the propagation of sound on each side of its origin.

Trinity College, Oxford, Ociober I.

\section{On some Effects of Lightning.}

THE twisting of one of the two trees near St. Albans, which were struck in such a remarkable manner by lightning, may well have been caused by the fall of the top of the tree, as Mr. Griffith suggests, and not directly by the lightning.

I have been unsuccessful in ascertaining whether the core of the tree is situated nearer that sicle where the explosion seems to have been most violent; but a more detailed examination only enforces the conclusion which Mr. Griffith and I arrived at, that the explosion must bave occurred inside the stem, if not actually at the core of the tree.

The effects in this case can meet with no explanation from the supposition that the lightning passed between the bark and the tree, generating thereby sufficient steam to blow off the bark and shatter the stem-an explanation which Mr. Maclear suggests in his letter of September 25. . I doubt if any source of heat would ever convert water so quickly into steam as to endow it with the power which dynamite has of shattering a hard object lying in contact with it, while the gases formed are restrained by the comparatively feeble resistance of the bark and outer air ; nor can we suppose that sufficient heat could pass into the stem to generate steam there adequate for such an explosion, even if the uncharred condition of the wood did not prove incontestably that the temperature had not been raised very high. It seems more probable to me that such explosions must be caused by the lightning electrolysing the liquids in the stem, and 